\title{
Tool Condition Monitoring in Turning Using Statistical Parameters of Vibration Signal
}

\author{
Hakan Arslan and Ali Osman Er \\ Department of Mechanical Engineering, Faculty of Engineering, Kirikkale University, 71451 Kirikkale, Turkey
}

\begin{abstract}
Sadettin Orhan
Department of Mechanical Engineering, Faculty of Engineering and Natural Sciences, Ankara Yıldırım Beyazıt University, Ankara, Turkey
\end{abstract}

\author{
Ersan Aslan \\ The Ministry of Science, Industry, and Technology, Ankara, Turkey
}

(Received 23 September 2015; accepted 10 June 2016)

\begin{abstract}
In this study, the relationship between vibration and tool wear is investigated during high-speed dry turning by using statistical parameters. It is aimed to show how tool wear and the work piece surface roughness changes with tool vibration signals. For this purpose, a series of experiments were conducted in a CNC lathe. An indexable CBN tool and a $16 \mathrm{MnCr} 5$ tool steel that was hardened to $63 \mathrm{HRC}$ were both used as material twins in the experiments. The vibration was measured only in the machining direction using an acceleration sensor assembled on a machinery analyzer since this direction has more dominant signals than the other two directions. In addition, tool wear and work piece surface roughness are measured at different cutting time intervals where the cutting speed, radial depth of cut, and feed rate are kept constant. The vibration signals are evaluated using statistical analysis. The statistical parameters in this study are the Root Mean Square (RMS), Crest Factor, and Kurtosis values. When the flank wear increases, the Kurtosis value and RMS also increase, but the Crest factor exhibited irregular variations. It is concluded that these statistical parameters can be used in order to obtain information about tool wear and work piece surface roughness.
\end{abstract}

\section{NOMENCLATURE}

\section{RMS Root Mean Square}

KV Kurtosis Value

CF Crest Factor

FFT Fast Fourier Transform

\section{AE Acoustic Emissions}

\section{INTRODUCTION}

Products can be manufactured by using various methods such as casting, extruding, and pressing. In the past, machining has been the most popular of the various manufacturing processes. The necessity of keeping in low level of product cost is dictated by competition among the manufacturers, so this is required to manufacture products with high quality. One very important factor that affects the product quality is tool wear. Tool wear in any machining process affects surface quality and dimensional accuracy of the product, which is why tool wear monitoring is an important issue to consider. Tool wear monitoring methods are classified as direct and indirect. ${ }^{1,2} \mathrm{~A} \mathrm{Di}-$ rect method is implemented by using optical devices to measure the geometry of the wear land. The indirect method is based on the acquisition of measured values of process variables (such as the change of size of the work piece, cutting force, temperature, vibration, spindle motor current, acoustic emission, and surface roughness) and establishes the relationship between tool wear and the process values of variables. ${ }^{2}$ Among the process variables, vibration supplies the best information about tool condition. Some of the advantages of vibration measurement include ease of implementation and the fact that no modifications to the machine tool or the work piece fixture are required. ${ }^{3}$ Past studies have been divided into two main groups: Acoustic Emission RMS and Vibration monitoring methods. Many researchers focused on the Acoustic Emission RMS method for machining applications for a long time. However, the studies based on vibration monitoring are relatively less than the others.

Ghani et al. ${ }^{1}$ presented a study of tool life, surface finish, and vibration while turning a nodular cast iron using ceramic tool. They concluded that the surface finish was found to be almost constant with the progression of the flank wear under different cutting conditions. They also observed that vibration during cutting decreased as the speed increased and at a low depth of cut, the vibration remained almost constant with the increase of flank wear. Risbood et al. ${ }^{4}$ conducted several experiments to predict surface roughness and dimensional 
deviation by measuring cutting forces and vibrations in turning process. In their study, surface finish could be predicted within a reasonable degree of accuracy by taking the acceleration of the radial vibration of tool holder as a feedback. Ramakrishna Rao et al. ${ }^{5}$ observed that tool acceleration amplitude at the first natural frequency of the tool decreased at the beginning, approached a minimum at the critical wear, and increased again, in turning EN 31 steel using uncoated indexable carbide inserts. They concluded from their findings that minimum tool acceleration could be used as an indicator of critical tool wear and the acceleration could be used to monitor wear on-line. Abouelatta and $\mathrm{Madl}^{6}$ aimed to find a correlation between surface roughness and cutting vibrations in turning and to derive mathematical models for predicted roughness parameters and machine tool vibrations. They concluded that the method could be useful in predicting roughness parameters as a function of cutting parameters and tool vibration.

The vibration signals could be converted to a more meaningful state by using the statistical analysis method. The statistical analysis method is the most suitable one with random signals when compared with other signal analysis methods. This was based on the assumption of deterministic signals, which was not applicable. The statistical analysis method has been successfully applied in different branches ${ }^{7-11}$ but there is little work related to machining process. El-Wardany et al. ${ }^{12}$ conducted experiments for on-line drill wear monitoring and breakage. Their results showed that the KV increased drastically with drill breakage while frequency analysis revealed sharp peaks indicating drill breakage. Scheffer and Heyns ${ }^{13}$ investigated the tool wear in turning by using vibration and strain measurements. The experiments were made for this purpose. They helped us to obtain KV and CF features, which displayed significant trends with increasing tool wear. Kumar et al. ${ }^{14}$ considered statistical methods such as time series modeling technique for monitoring. This technique was used to extract parameters called features, which represented the state of the cutting process and the cutting tool condition in a turning process. They had extracted a maximum amount of information from force/vibration signals that were acquired during machining. Other parameters, such as static cutting force and power of the dynamic signal (force/vibration) were also studied here as features. Dimla ${ }^{15,16}$ described a tool-wear monitoring procedure in a metal turning operation to correlate vibration signals to tool wear. The results showed that time domain features were deemed to be more sensitive to cutting condition than tool wear, whereas frequency based features correlated well with the tool wear. Other studies presented a review of some of the methods that were employed in tool condition monitoring. Particular attention was paid to the manner in which sensor signals from the cutting process have been harnessed and used in the development of tool condition monitoring systems. Thomas and Beauchamp ${ }^{17}$ focused on the collection and analysis of cutting-force, tool-vibration, and tool-modal-parameter data that were generated by the lathe dry turning mild carbon steel samples at different speeds, feeds, depths of cut, tool nose radii, tool lengths, and work piece lengths. They analyzed the effect of each cutting parameter on tool stiffness, damping, and yielded an empirical model for predicting the behavior of the tool stiffness variation. Moufki et al. ${ }^{18}$ presented an analytical model of chatter vibration in orthogonal cutting in feed direction and contributed to the understanding of the self-excited vibration phenomenon, for which an experimental study was first carried out. Vibration signals, surface roughness, and chip morphologies were analyzed for different sets of cutting conditions in order to define the stability limits of the process. They found that the predicted stability limits compared well with those obtained from the experimental tests and the literature.

Some investigators considered acoustic emission signals for tool wear detection. Jemielniak and Otman ${ }^{19}$ used a statistical signal-processing algorithm to identify the RMS, skew, and $\mathrm{KV}$ of acoustic emission signals for the detection of catastrophic tool failure and concluded that the skew and KV may be better indicators of tool failure than RMS values. They were found to be highly sensitive to changes in tool conditions and gave promising results with regard to chipping as well as tool breakage detection. J. Sun et al. ${ }^{20}$ used a signal-processing algorithm in order to identify RMS, skew, and the KV of AE signals. It was concluded that the skew and $\mathrm{KV}$ may be better indicators of tool failure than RMS values. Roget et al. ${ }^{21}$ carried out machining tests from which the sensed AE signals; the cutting operation were used to predict the state of the cutting tool. Several parameters of the AE were recorded (i.e., RMS, mean, and peak values). They concluded that such a task could only be successfully accomplished under specific and limited conditions. Further statistical features, such as the variance, $\mathrm{KV}$, and the skew were extracted from the recorded parameters. Dornfeld ${ }^{22}$ claimed that the changes in the skew and $\mathrm{KV}$ of the AE RMS signals could effectively indicate tool wear. Ravindra et al. ${ }^{23}$ described an indirect technique for the monitoring of cutting tool conditions. The detection and analysis of $\mathrm{AE}$ that was generated during the machining of C-60 steel with a multilayer-coated carbide tool was carried out in order to monitor the tool wear. The possibility of applying $\mathrm{AE}$ methods as an on-line tool wear monitoring technique was investigated. Kamarthi et al. ${ }^{24}$ considered that the wavelet transform representation of $\mathrm{AE}$ signals was effective in extracting $\mathrm{AE}$ signal features that were sensitive to gradually increasing flank wear.

The main objective of the present study was to find the relationship between statistical vibration parameters, tool wear, and surface roughness by changing the cutting time during high speed turning operation. For this purpose, a series of experiments were performed in a high speed CNC lathe. A CBN tool with a single cutting edge and a $16 \mathrm{MnCr} 5$ tool steel with $63 \mathrm{HRC}$ hardness as the work piece were both used. The vibrations were measured only in the machining direction by using a sensor that was assembled on a vibration analyzer, since the signals in this direction were more dominant than the other two directions after each pass. The machining was interrupted after every fifth experiment and the amount of the tool flank wear 


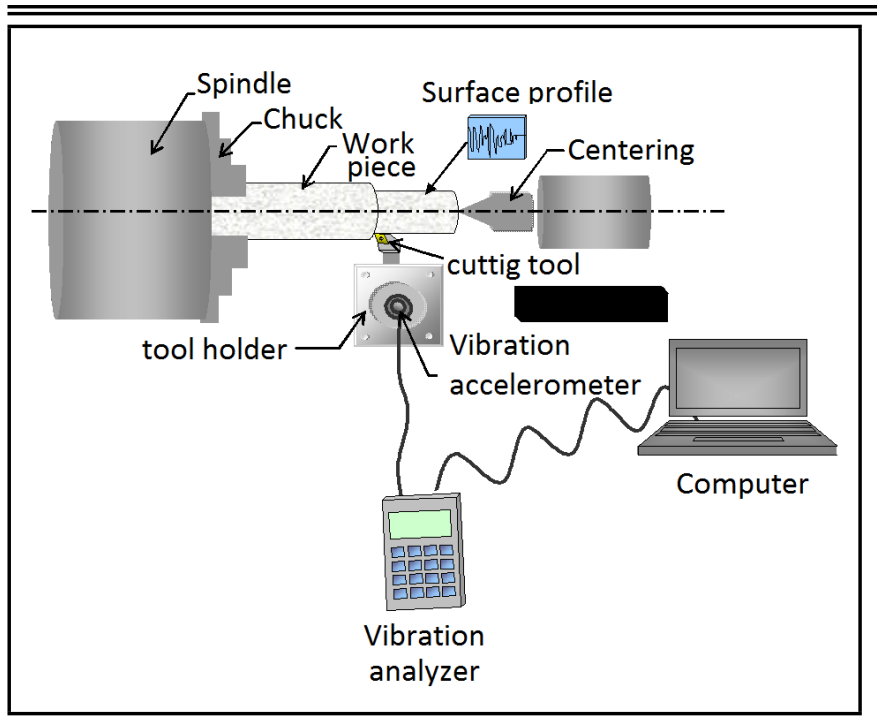

Figure 1. The schematic of the CNC lathe Experimental Setup.

Table 1. The properties of the work piece material.

\begin{tabular}{|l|c|}
\hline \multicolumn{2}{|c|}{ Workpiece material } \\
\hline Type & $16 \mathrm{MnCr} 5$ \\
\hline Composition $(\%)$ & $0.49 \mathrm{Si}, 0.28 \mathrm{Mn}, 0.33 \mathrm{Al}, 96.0 \mathrm{Fe}, 2.39 \mathrm{Ni}, 0.5 \mathrm{Cr}$. \\
\hline Hardness & $63 \mathrm{HRC}$ \\
\hline \multirow{3}{*}{ Dimensions } & Diameter: $40 \mathrm{~mm}$ \\
\cline { 2 - 2 } & Overall length: $250 \mathrm{~mm}$ \\
\cline { 2 - 2 } & Cutting length: $170 \mathrm{~mm}$ \\
\hline
\end{tabular}

and contact length at the chip-tool interface was measured by a toolmaker's microscope. The collected vibration data were processed by using statistical analysis methods. The statistical parameters, RMS, CF, and KV were thus obtained.

\section{THE EXPERIMENTAL PROCEDURE}

The cutters were changed for each pass and the tool vibrations were determined on the tool. Lateral surface wears were examined by scanning electron microscope at $200 \times$ magnification.

\subsection{Turning Machine, Cutting Tool, and Cut- ting Parameters}

A series of turning experiments were conducted without any coolant in a PC-35 JHONNFORD CNC high speed turning machine. The experimental set up schematic is shown in Fig. 1. The tests were carried out by using a CBN cutting tool, which was clamped on a tool holder without any coolant. The work piece material was a cylindrical block of $16 \mathrm{MnCr} 5$ tool steel hardened to 63 HRC. The cutting speed, radial depth of cut, and feed rate were kept constant at $300 \mathrm{~mm} / \mathrm{min}, 0.5 \mathrm{~mm}$, and $0.16 \mathrm{~mm} / \mathrm{rev}$, respectively. The properties of the work piece and tooling materials are given in Table 1 and 2, respectively.

\subsection{Machining Parameters}

The experiments were performed under dry conditions. The tool life criterion was taken as $0.3 \mathrm{~mm}$ flank wear for all
Table 2. The properties of the tooling material.

\begin{tabular}{||c|c|}
\hline \multicolumn{2}{|c|}{ Tooling Material } \\
\hline Tool holder & PCLNR 25 25 M16 \\
\hline Tool type & CNGA120408S01025MT \\
\hline Tool material & CBN insert \\
\hline Tool holder clamping & Kenlever \\
\hline Insert angle $\left(^{\circ}\right)$ & 80 \\
\hline Cutting edge length $(\mathrm{mm})$ & 12 \\
\hline Insert thickness $(\mathrm{mm})$ & 4 \\
\hline Nose radius $(\mathrm{mm})$ & 0,8 \\
\hline Approach angle $\left(^{\circ}\right)$ & 95 \\
\hline Relief angle $\left(^{\circ}\right)$ & 5 \\
\hline Rake angle $\left(^{\circ}\right)$ & -6 \\
\hline
\end{tabular}

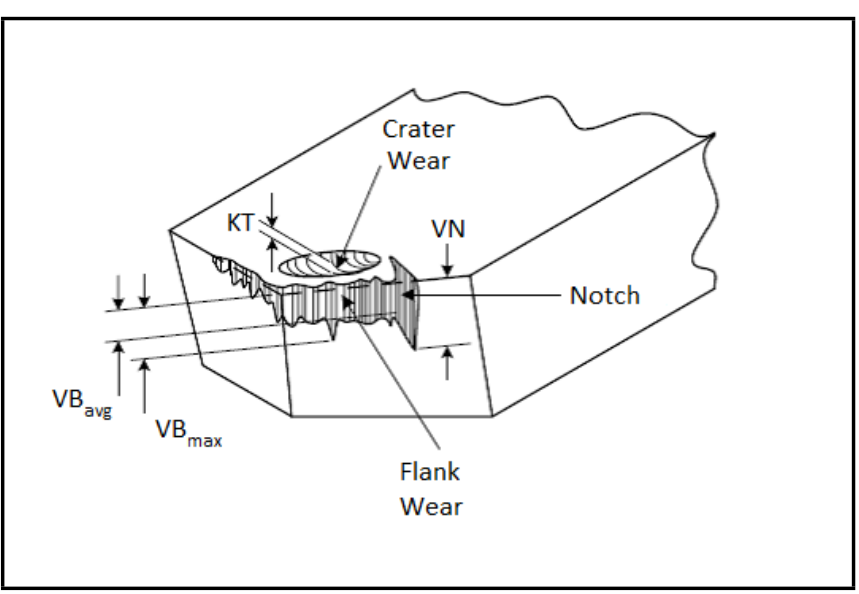

Figure 2. The wear types in a cutting tool. ${ }^{28}$

the tools. The flank wear and surface roughness measurements were taken after each pass of the cutter tools. The PCBN KB5625 cutting tools were used for turning variables, as shown in Table 3.

\subsection{Measurement of Tool Wear}

The action of one or several of these mechanisms results in a number of tool wear types. Several classifications of these wear types were proposed with minor differences amongst them. ${ }^{25-27}$ The most common wear types include flank wear, crater wear, and notch wear, which are all shown in Fig. 2.

Flank wear is the most frequently used wear type to determine when a tool is considered to be worn. This type of wear is mostly the result of the abrasion mechanism between the clearance face and the new machined surface. The ideal cutting conditions consider flank wear as the only type that is "acceptable" and try to keep it at its lowest progressive rate. ${ }^{25}$

\section{VIBRATION MEASUREMENT}

The vibration signals were gathered by a piezoelectric accelerometer and processed with a CSI 2110 vibration analyzer. The accelerometer (CSI 350) and PCB 603C01, were able to sense vibration signals from $0.5 \mathrm{~Hz}$ up to $10000 \mathrm{~Hz}$. The sensitivity was $100 \mathrm{mV} / \mathrm{g}$, and the measurement range was $\pm 50 \mathrm{~g}$. Its resonance frequency was $25 \mathrm{kHz}$. The analyzer consisted of one accelerometer, a memory in which the signals were 
Table 3. The PCBN cutting tools that were used for turning variables.

\begin{tabular}{|c|c|c|c|c|c|c|c|c|c|c|c|}
\hline EXP. & $\begin{array}{c}\text { Cutting } \\
\text { Tool }\end{array}$ & Cutter & $\begin{array}{l}\text { Cutting } \\
\text { Media }\end{array}$ & Lathe & $\begin{array}{l}\text { Time } \\
(\min )\end{array}$ & $\begin{array}{c}\text { ap } \\
(\mathrm{mm})\end{array}$ & $\begin{array}{c}\mathrm{f} \\
(\mathrm{mm} / \mathrm{rev})\end{array}$ & $\begin{array}{c}\mathrm{Vc} \\
(\mathrm{m} / \mathrm{rev})\end{array}$ & $\begin{array}{c}\mathrm{n} \\
(\mathrm{rpm})\end{array}$ & $\begin{array}{c}\mathrm{L} \\
(\mathrm{mm})\end{array}$ & $\begin{array}{c}\text { D2 } \\
(\mathrm{mm})\end{array}$ \\
\hline Exp. 1. & \multirow{5}{*}{ 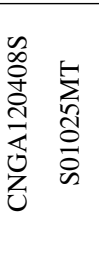 } & \multirow{5}{*}{ 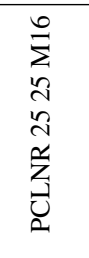 } & \multirow{5}{*}{$\vec{a}$} & \multirow{5}{*}{ 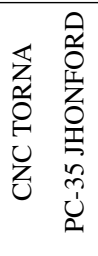 } & 8 & \multirow{5}{*}{0.5} & \multirow{5}{*}{0.16} & \multirow{5}{*}{300} & \multirow{5}{*}{2387} & \multirow{5}{*}{170} & 32 \\
\hline Exp. 2. & & & & & 12 & & & & & & 28 \\
\hline Exp. 3. & & & & & 16 & & & & & & 24 \\
\hline Exp. 4. & & & & & 20 & & & & & & 20 \\
\hline Exp. 5. & & & & & 24 & & & & & & 16 \\
\hline
\end{tabular}

Table 4. The parameters for vibration measurements.

\begin{tabular}{|c|c|}
\hline Number of spectral line & 800 \\
\hline Number of average & 6 \\
\hline Number of gathered data & 1024 \\
\hline Window type & Hanning \\
\hline Spectral average mode & Normal \\
\hline Frequency range & $60-3000 \mathrm{~Hz}$ \\
\hline
\end{tabular}

stored, electrical circuits that converted time domain signals to frequency domain signals using the FFT process, and a port through which vibration signals were transferred into a computer. The used accelerometer was mounted magnetically onto the surface of the tool holder. The parameters for collecting vibration signal are given in Table 4. It was observed that the dominant vibration signals took place between $60-3000 \mathrm{~Hz}$ in the machining test. Thus, this frequency range was chosen as frequency limits.

In the experiments, since no significant wear and vibration levels were observed on the tool after the first few passes of the tool on the work piece along the cutting length of $170 \mathrm{~mm}$, it was decided that tool wear, tool vibration, and surface roughness of work piece measurements were to be taken after every five passes with changing cutting time. Vibration signals were recorded during cutting operation and tool flank wear and surface roughness of the work piece were measured after the turning was stopped. The maximum flank wear of the tool was measured by using an optical microscope.

\section{STATISTICAL ANALYSIS}

The collected vibration data from the experiments were processed using statistical analysis methods and the statistical parameters considered were RMS, CF, and KV. The statistical parameters were calculated from the time domain data. The $\mathrm{KV}$ and $\mathrm{CF}$ allowed the analysis of the distribution of the vibration amplitudes to be contained in a time domain signal.

The root mean square value gave an indication of the continuous or steady state amplitude in a time varying signal. RMS is defined as the square root of the average of the sum of the squares of an infinite number of samples of the signal, and the variance is the second-order central moment. The variance and RMS values were calculated from the equation shown below:

$$
\begin{aligned}
\text { Varience }: \sigma^{2} & =\frac{\sum_{i=1}^{N}\left(x_{i}-\bar{x}\right)^{2}}{N} ; \\
\text { RMS } & =\sqrt{\frac{\sum_{i=1}^{N} x_{i}{ }^{2}}{N} ;}
\end{aligned}
$$

where $x_{i}$ was the measured vibration data, acceleration $\mathrm{mm} / \mathrm{s}^{2}$, $\bar{x}$ is the mean of $x_{i}$ values, $N$ was the number of samples in the range, and $\sigma$ was the standard deviation considered.

The KV was a higher-order statistical attribute of a time series and the values corresponded to the normalized fourth central moment. This was shown for a Gaussian distribution and a brief description of each is provided below:

Kurtosis Value $=$

$$
\frac{\mathrm{M}_{4}}{(\text { StandardDeviation })^{4}}=\frac{\frac{1}{N} \sum_{i=1}^{N}\left(x_{i}-\bar{x}\right)^{4}}{(\sigma)^{4}} .
$$

The CF corresponded to the ratio between the crest value (maximum absolute value reached by the function representative of the signal during the considered period of time) and the RMS value (efficient value) of the signal:

Crest Factor $=$

$$
\frac{\text { Maximum } C \text { rest } V \text { alue }}{\text { RMS value }}=\frac{\max \left(\left|x_{i}\right|\right)}{\sqrt{\frac{\sum_{i=1}^{N} x_{i}{ }^{2}}{N}}}
$$

The application of distribution moments, such as $\mathrm{KV}$ and skewness, have been well established in the analysis of vibration signals in tool condition monitoring and to extreme values on both sides of the distribution.

\section{RESULTS}

In the five experiments, the amount of flank wear on cutting tools was below the $300 \mu \mathrm{m}$, which is the threshold used in ISO $3685^{29}$ tool life testing with single-point turning tools. Typical flank wear of the CBN cutting tool obtained after the first experiment is presented in Fig. 3. Figure 3 shows that the lateral surface wear occurred in the notch form which leads to an increase in work piece surface roughness. Increasing the 


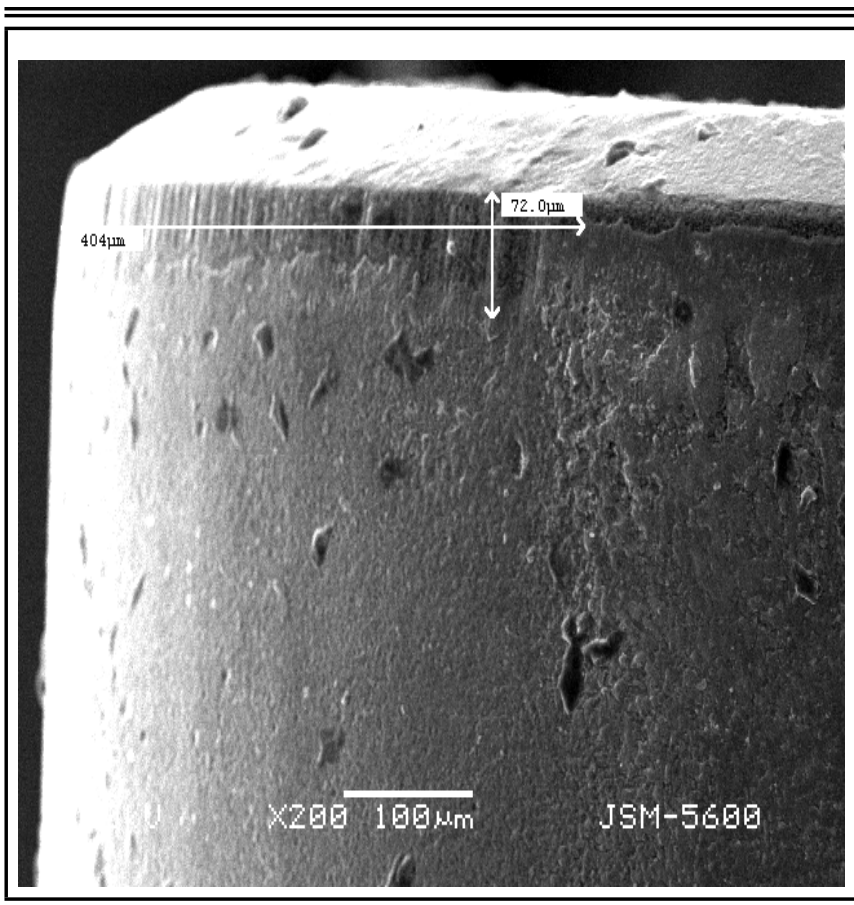

Figure 3. The flank wear pattern on the PCBN cutting tool at the first experi$\operatorname{ment}\left(V B_{\max }=72 \mu \mathrm{m}\right)$.

tool wear deteriorates the work piece surface quality, which then increases the tool vibrations, thus causing further degradation of the surface quality.

In laboratories, tool wear is generally used as a life criterion because it is easy to determine quantitatively. The amount of flank wear is often used as the criterion because flank wear influences the surface roughness and accuracy of work material. When an abrasion is the main cause of flank wear, the wear pattern is relatively uniform and easy to measure. A standard measure of tool life was the formation of a flank wearland, VB, with length of $300 \mathrm{~mm}$, although this was more related to a life limited by failure than by surface finish or accuracy. ${ }^{30}$

Typical flank wear of CBN cutting tool was obtained in the end of the experiments (fifth experiment) as shown in Fig. 4.

It was concluded that the notch form wear surface, which was observed after the fifth experiment, was caused by carbide and martensite phases within the tool microstructure under the cubic boron nitrate coating. Wear particles did not cause the scratches on the cutting tool because their hardness was less than that of the tool.

The values of flank wear and surface roughness were obtained for different cutting times, as shown in Figs. 5 and 6, respectively. Figure 5 can be divided into three stages: first stage (from $0 \mathrm{~min}$ to $8 \mathrm{~min}$.), second stage (from $8 \mathrm{~min}$ to $16 \mathrm{~min}$.), and third stage (from $16 \mathrm{~min}$ to $24 \mathrm{~min}$.). The wear appears to grow more rapidly at the initial stage, grows at a lower steady rate up to the third stage, and then grows at a higher rate at the final stage.

In a turning process with a new cutter, the surface roughness follows these stages during cutting time: in the first stage, the surface roughness rapidly increases with time. In the second stage, it remains stationary. At the last stage, it increases rapidly again. Figure 6 shows the increase of the surface

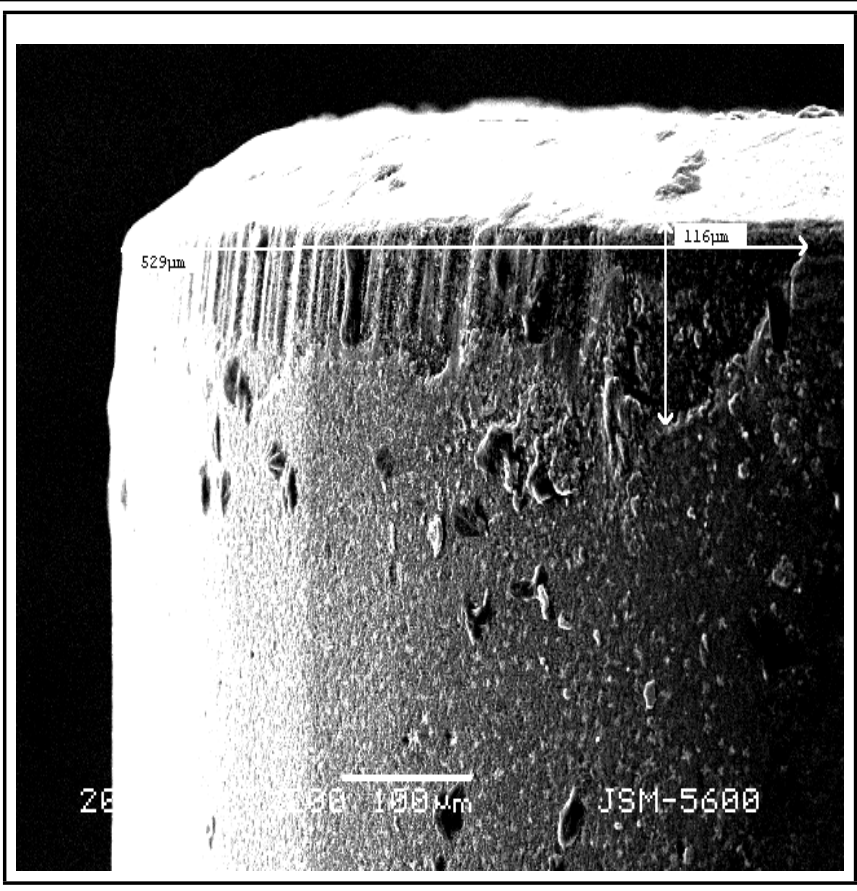

Figure 4. The flank wear pattern on the PCBN cutting tool at the fifth experiment $\left(V B_{\max }=116 \mu \mathrm{m}\right)$.

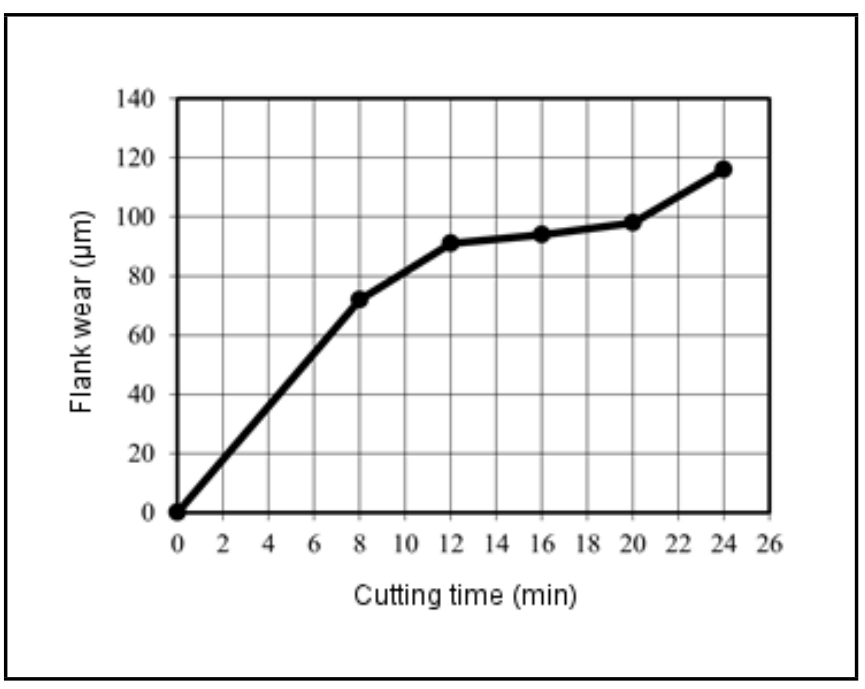

Figure 5. The relationship between the Cutting time and the Flank wear for $V_{c}=300 \mathrm{~m} / \mathrm{min}, a_{p}=0,5 \mathrm{~mm}$, and $f=0,16 \mathrm{~mm} / \mathrm{rev}$.

roughness with a cutting time of about 8 minutes. However, when the cutting time went beyond 8 minutes, the $R_{a}$ values showed some fluctuations. However, the $R_{a}$ values were taken as constants because their deviations were relatively small. The surface roughness decreased after 20 minutes of cutting time from the cutter nose radius as a result of flank wear.

Figure 7 shows RMS value obtained from vibration amplitude versus the flank wear. Vibration amplitude increases with increasing the flank wear from $72 \mu \mathrm{m}$ to $94 \mu \mathrm{m}$. The RMS value seemed to be steady for flank wear values between $94 \mu \mathrm{m}$ and $98 \mu \mathrm{m}$. Moreover, it sharply increased again with the increasing flank wear from $98 \mu \mathrm{m}$ to $116 \mu \mathrm{m}$. It is expected that RMS increases along with the increasing the flank wear, as seen in Fig. 7.

KV obtained from the vibration amplitude against flank 


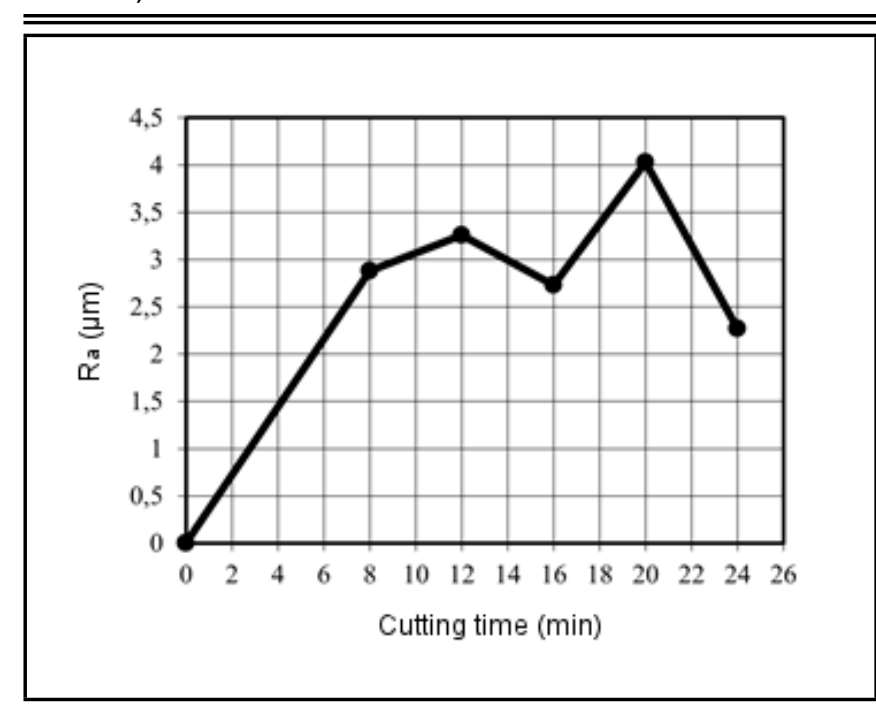

Figure 6. The relationship between the Cutting time and Surface Roughness for $V_{c}=300 \mathrm{~m} / \mathrm{min}, a_{p}=0,5 \mathrm{~mm}$, and $f=0,16 \mathrm{~mm} / \mathrm{rev}$.

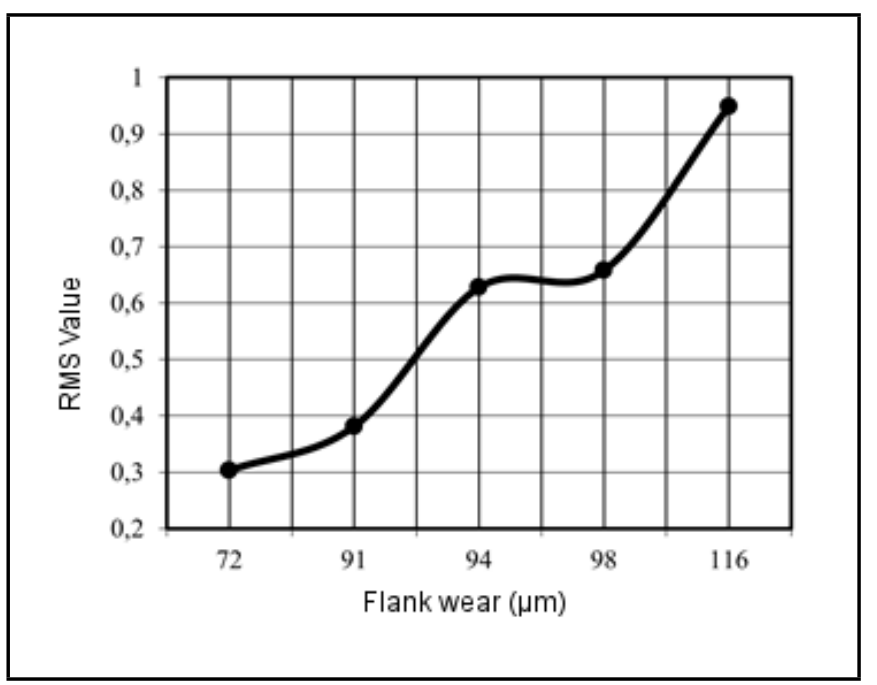

Figure 7. The relationship between the Flank wear and the RMS values for $V_{c}=300 \mathrm{~m} / \mathrm{min}, a_{p}=0,5 \mathrm{~mm}$, and $f=0,16 \mathrm{~mm} / \mathrm{rev}$.

wear is shown in Fig. 8. It can be seen that the KV showed an increasing tendency with increasing the flank wear. However, very slight increase was observed within the initial stage of the wear from $72 \mu \mathrm{m}$ to $94 \mu \mathrm{m}$. The KV increase was more significant with the flank wear between $94 \mu \mathrm{m}$ to $98 \mu \mathrm{m}$, after the $\mathrm{KV}$ is reached to 3.3 and bigger values.

Another statistical parameter that was used to evaluate tool wear was $\mathrm{CF}$. The $\mathrm{CF}$ value obtained by the vibration amplitude against flank wear is given in Fig. 9. It can be seen that the CF showed an increasing tendency with increasing flank wear. However, a very slight increase was observed within the initial stage of the wear from $72 \mu \mathrm{m}$ to $94 \mu \mathrm{m}$. The CF increase was more significant with the flank wear between $94 \mu \mathrm{m}$ to $98 \mu \mathrm{m}$. It was expected that the CF value would increase with the increasing flank wear.

Figure 10 presents changes in the surface roughness value with respect to the CF. The obtained curve exhibited four different regions. Surface roughness was increased above 3.025 and 3.36 CF's while moderate decrease was observed from 2.965 to 3.025 and from 3.226 to $3.36 \mathrm{CF}$ values. The rela-

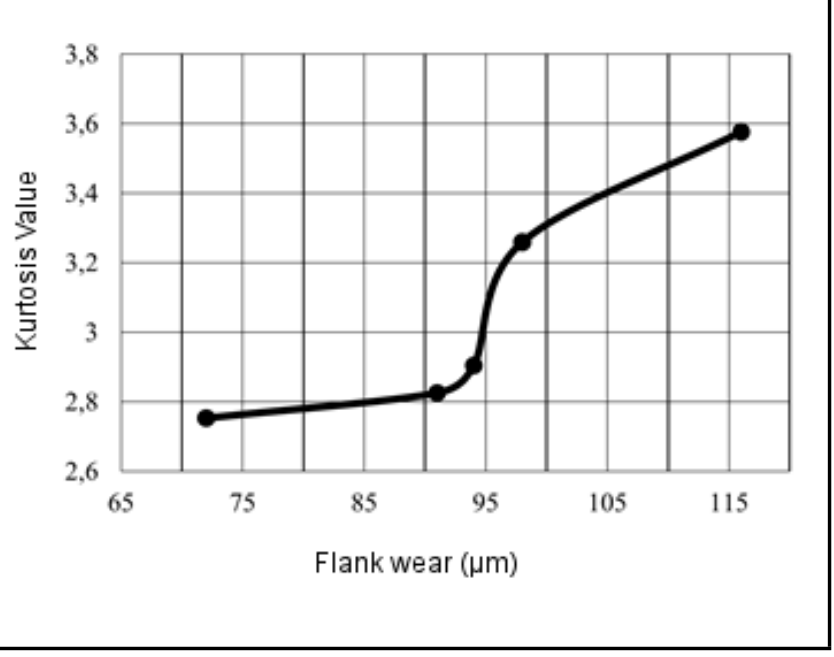

Figure 8. The relationship between the Flank Wear and the Kurtosis value for $V_{c}=300 \mathrm{~m} / \mathrm{min}, a_{p}=0,5 \mathrm{~mm}$, and $f=0,16 \mathrm{~mm} / \mathrm{rev}$.

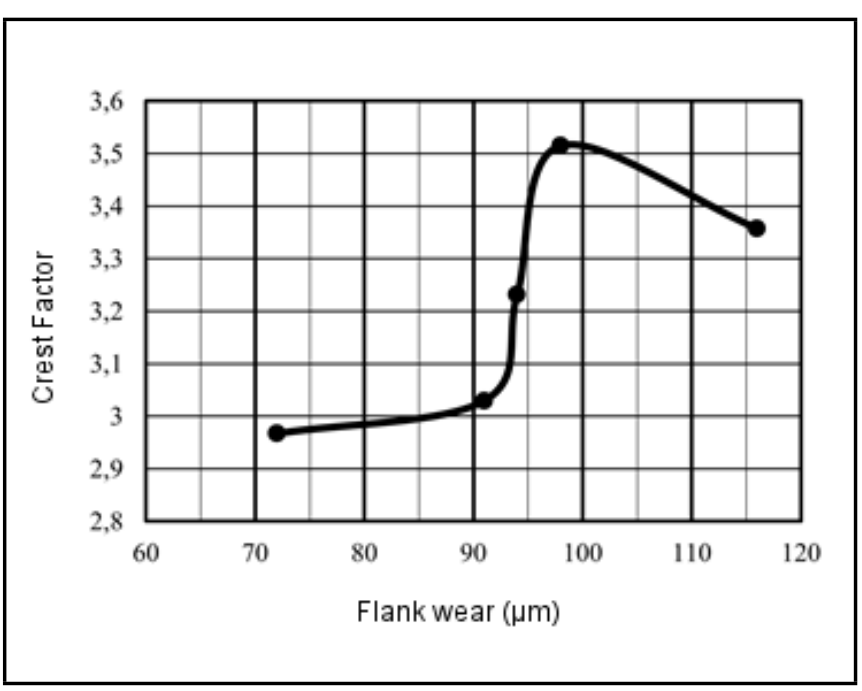

Figure 9. The relationship between the Flank wear and the Crest factor for $V_{c}=300 \mathrm{~m} / \mathrm{min}, a_{p}=0,5 \mathrm{~mm}$, and $f=0,16 \mathrm{~mm} / \mathrm{rev}$.

tionship between the surface roughness and the CF exhibits positive correlation except for decreasing parts of the figure. We anticipated that this part may be constant. Some deviations could have been due to experimental conditions.

The changes in surface roughness with respect to $\mathrm{KV}$ are seen in Fig. 11. This curve is similar to the curve present in Fig. 10. The surface roughness decreased between the KV values of 2.82 and 3.25. The increase of KV was more significant when the surface roughness was between 3.25 and 3.58 .

A similar relation was almost valid for the change in RMS values with increasing the surface roughness, as shown in Fig. 12. In the first region, both the surface roughness and RMS increased, in the second region, the surface roughness decreased along with the increasing RMS, and in the last region, the surface roughness increased sharply with the increasing RMS values. As such, surface roughness decreased with the decreasing RMS value. This shows that decreasing the vibration leads to an increase in the surface quality. 


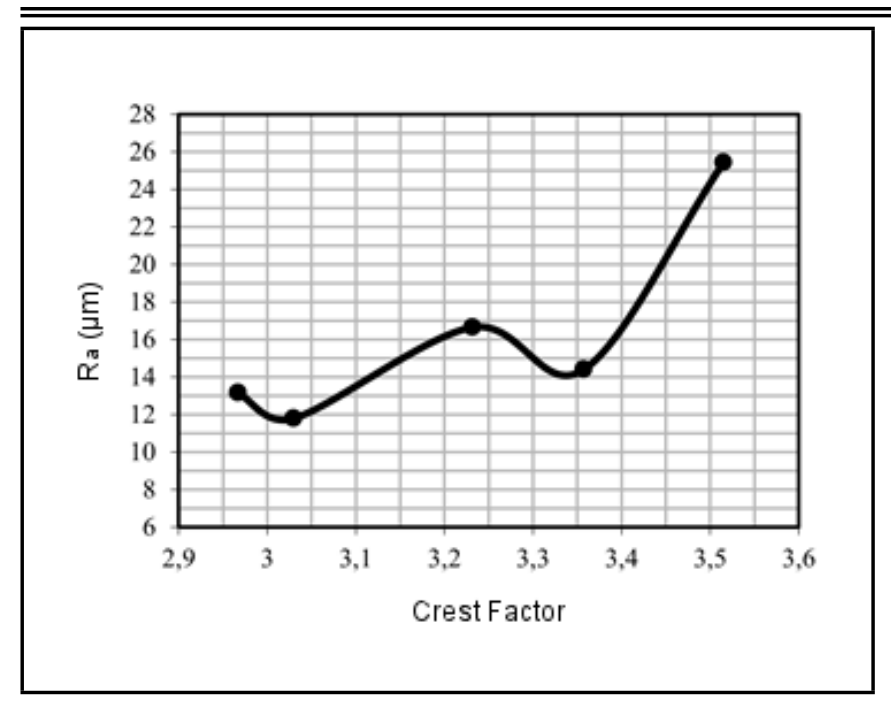

Figure 10. The relationship between the Surface Roughness ( $\mathrm{Ra}$ ) and the Crest Factor for $V_{c}=300 \mathrm{~m} / \mathrm{min}, a_{p}=0,5 \mathrm{~mm}$, and $f=0,16 \mathrm{~mm} / \mathrm{rev}$.

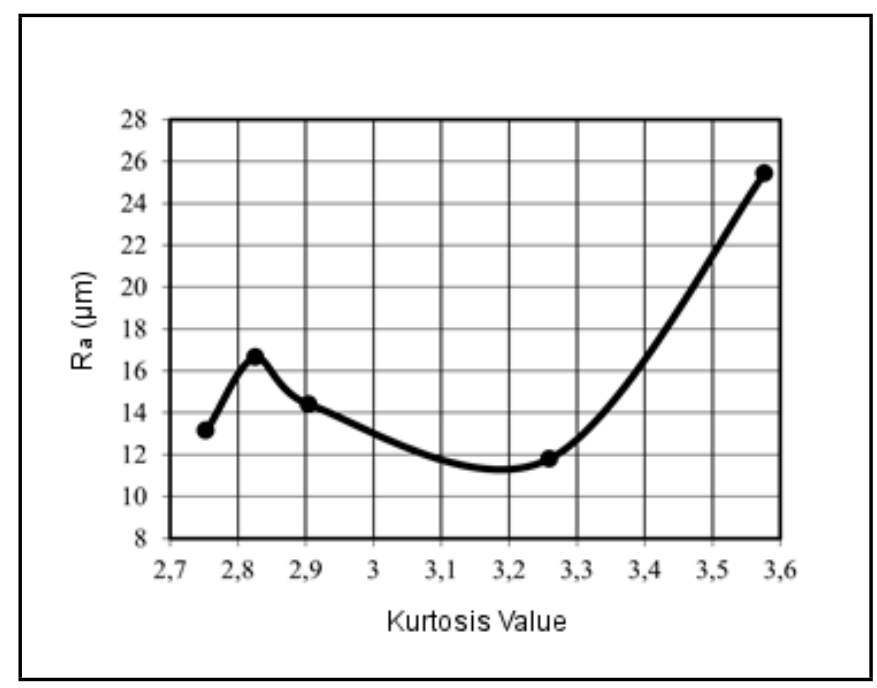

Figure 11. The relationship between the Surface Roughness (Ra) and the Kurtosis value for $V_{c}=300 \mathrm{~m} / \mathrm{min}, a_{p}=0,5 \mathrm{~mm}$, and $f=0,16 \mathrm{~mm} / \mathrm{rev}$.

\section{CONCLUSION}

In this study, the flank wear and the surface roughness were investigated under high speed turning conditions. The relationship between cutting time on the one hand and flank wear and surface roughness on the other was investigated. Moreover, the statistical parameters such as the $\mathrm{KV}, \mathrm{CF}$, and, RMS were obtained from vibration data and the effect of the flank wear and surface roughness on these parameters was studied.

The flank wear increased with the increasing cutting time as expected during the cutting process. The surface roughness presented an irregular variation with increasing the cutting time but this behavior approximately matches with the general trend except for some difference. The KV and RMS increased when the flank wear increased, but the CF followed irregular variations.

The change in surface roughness with the $\mathrm{CF}, \mathrm{KV}$, and RMS exhibited similar curves. It is concluded that the $\mathrm{CF}, \mathrm{KV}$, and RMS parameters can be used in order to obtain information about tool wear and work piece surface roughness. However,

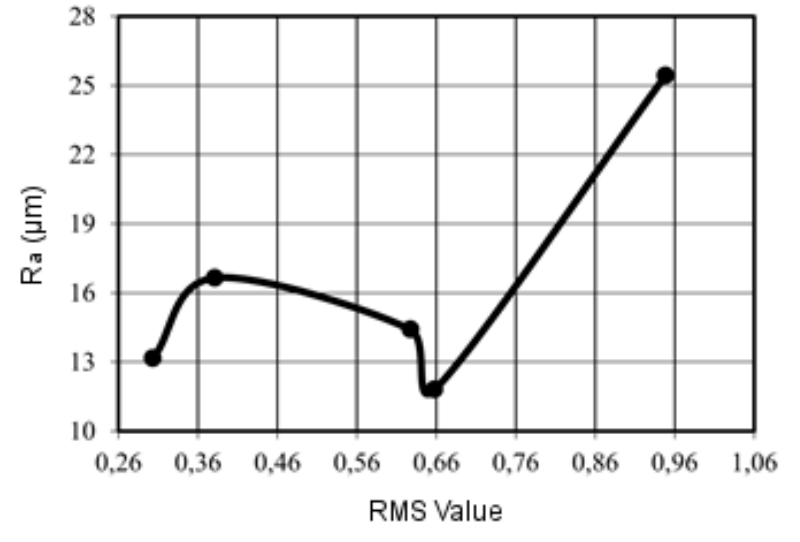

Figure 12. The relationship between the Surface Roughness ( $\mathrm{Ra}$ ) and the RMS value for $V_{c}=300 \mathrm{~m} / \mathrm{min}, a_{p}=0,5 \mathrm{~mm}$, and $f=0,16 \mathrm{~mm} / \mathrm{rev}$.

for this purpose, more experiments must be done with varying cutting parameters, different work parts and tools.

Although real-like information can be obtained by evaluating vibration parameters such as RMS, $\mathrm{KV}$, and $\mathrm{CF}$, no clear information about the state of the work piece surface roughness can be obtained.

\section{REFERENCES}

1 A .K., Ghani, I. A., Choudhury Husni. Study of tool life, surface roughness and vibration in machining nodular cast iron with ceramic tool, J. Mater. Process. Technol., 127, 17-22, (2002). http://dx.doi.org/10.1016/S09240136(02)00092-4

2 S. C., Lin and C. J., Ting. Drill wear monitoring using neural networks, Int. J. Mach. Tools Manuf., 36 (4), 465-475, (1996). http://dx.doi.org/10.1016/0890-6955(95)00059-3

3 S., Braun and E., Lenz. Machine Tool Wear Monitoring: Mechanical Signature Analysis, Theory and Applications, Academic Presd Ltd., (1986).

4 K. A., Risbood, U. S., Dixit, and A. D., Sahasrabudhe, Prediction of surface roughness and dimensional deviation by measuring cutting forces and vibrations in turning process, J. Mater. Process. Technol., 132, 203-214, (2003). http://dx.doi.org/10.1016/S0924-0136(02)00920-2

5 P. K., Ramakrishna Rao, P., Prasad, M. V., Kumar, and V. Shantha. On-line wear monitoring of single point cutting tool using vibration techniques, Trends in NDE Science \& Technology; Proceedings of the 14th World Conference on Non-Destructive Testing, New Delhi, 8-13, 2, 1151-1156, December (1996). ISBN:90-5410-740-5

6 O. B., Abouelatte and J., Madl. Surface roughness prediction based on cutting parameters and tool vibrations in turning operations, J. Mater. Process. Technol., 118, 269-277, (2001). http://dx.doi.org/10.1016/S0924-0136(01)00959-1 
${ }^{7}$ R. B. W., Heng and M. J. M., Nor. Statistical analysis of sound and vibration signals for monitoring rolling element bearing condition, Appl. Acoust., 53 (1), 211-226, (1998). http://dx.doi.org/10.1016/S0003-682X(97)00018-2

8 B., Samanta and K. R., Al-Balushi, Artificial neural network based fault diagnostics of rolling element bearings using time-domain features, Mech. Syst Signal Pr., 17 (2), 317-328, (2003). http://dx.doi.org/10.1006/mssp.2001.1462

9 R. B., Randall. Applications of spectral kurtosis in machine diagnostics and prognostics, Key Eng. Mater, 293-294, 21-32, (2005). http://dx.doi.org/10.4028/www.scientific.net/KEM.293294.21

10 W. Q., Wang, F., Ismail, and M., Farid Golnaraghi, Assessment of gear damage monitoring techniques using vibration measurements, Mech Syst Signal Pr., 15(5), 905-922, (2001). http://dx.doi.org/10.1006/mssp.2001.1392

${ }^{11}$ S. K., Jeong, C. K., Myeong, J. R., Byung, and K. J., Young. Development of an on-line tool-life monitoring system using acoustic emission signals in gear shaping, Int. J. Mach. Tools Manuf., 39 (11), 1761-1777, (1999). http://dx.doi.org/10.1016/S0890-6955(99)00030-9

12 T. I., El-Wardany, D., Gao, and M. A., Elbestawi. Tool condition monitoring in drilling using vibration signature analysis, Int. J. Mach. Tools Manuf., 36 (6), 687-711, (1996). http://dx.doi.org/10.1016/0890-6955(95)00058-5

${ }^{13}$ C., Scheffer and P. S., Heyns. Wear monitoring in turning operations using vibration and strain measurements, Mech. Syst Signal Pr., 15 (6), 1185-1202, (2001). http://dx.doi.org/10.1006/mssp.2000.1364

${ }^{14}$ S. A., Kumar, H. V., Ravindra, and Y. G., Srinivasa, Inprocess tool wear monitoring through time series modelling and pattern recognition, Int. J. Prod. Res., 35 (3), 739-751, (1997). http://dx.doi.org/10.1080/002075497195687

15 D. E., Dimla. Sensor signals for tool-wear monitoring in metal cutting operations a review of methods, Int. J. Mach. Tools Manuf., 40, 1073-1098, (2000). http://dx.doi.org/10.1016/S0890-6955(99)00122-4

${ }^{16}$ D. E., Dimla. The correlation of vibration signal features to cutting tool wear in a metal turning operation, Int J AdvManuf Tech., 19 (10), 705-713, (2002). http://dx.doi.org/10.1007/s001700200080

17 M., Thomas and Y., Beauchamp. Statistical investigation of modal parameters of cutting tools in dry turning, Int. J. Mach. Tools Manuf., 43, 1093-1106, (2003). http://dx.doi.org/10.1016/S0890-6955(03)00131-7
18 A., Moufki, A., Devillez, M., Segreti, and D., Dudzinski, A semi-analytical model of non-linear vibrations in orthogonal cutting and experimental validation, Int. J. Mach. Tools Manuf., 46, 436-449, (2006). http://dx.doi.org/10.1016/j.ijmachtools.2005.04.017

${ }^{19}$ K., Jemielniak and O., Otman, Tool failure detection based on analysis of acoustic emission signals, J. Mater. Process. Technol., 76, 192-197, (1998). http://dx.doi.org/10.1016/S0924-0136(97)00379-8

20 J., Sun, M., Rahman, Y. S., Wong, and G. S., Hong. Multi classification of tool wear with support vector machine by manufacturing loss consideration, Int. J. Mach. Tools Manuf., 44, 1179-1187, (2004). http://dx.doi.org/10.1016/j.ijmachtools.2004.04.003

21 J., Roget, P., Souquet, and N., Gsib. Application of acoustic emission to the automatic monitoring of tool condition during machining, Mater. Eval., 46(2), 225-229, (1988).

22 D., Dornfeld. Application of acoustic emission techniques in manufacturing, NDT and E Int., 25 (6), 259-269, (1992). http://dx.doi.org/10.1016/0963-8695(92)90636-U

${ }^{23}$ H. V., Ravindra, Y. G., Srinivasa, and R., Krishnamurthy. Acoustic emission for tool condition monitoring in metal cutting, Wear, 212, 78-84, (1997). http://dx.doi.org/10.1016/S0043-1648(97)00137-3

${ }^{24}$ S., Kamarthi, S., Kumara, and P., Cohen, Wavelet representation of acoustic emission in turning process. Intell. Eng. Syst. Artif. Neural Network, 5, 861-866, (1995). http://dx.doi.org/10.1115/1.538886

25 Modern metal cutting: a practical handbook, 1st English ed., Sandvik Coromant, Sandviken, Sweden, (1994).

26 J. A., Schey. Introduction to manufacturing processes, 2nd ed. McGraw-Hill, New York, (1987).

27 M. C., Shaw. Metal Cutting Principles, Oxford University press, New York, (2005).

${ }^{28}$ H. O., Mendoza. Tool Wear Detection and Self-Induced Vibrations Control In Turning Operations, PhD Thesis, University of Texas at Austin, (2002).

29 ISO Standard No 3685, Tool-life testing with single-point turning tools, (1993).

30 T., Childs, K., Maekawa, T., Obikawa, and Y., Yamane. Metal Machining Theory and Applications, Arnold Publishing, London, (2000). 